\title{
Estudios hematológicos y patológicos comparativos de cerdos inoculados con un aislado de campo y el serotipo 5 ATCC de Actinobacillus pleuropneumoniae ${ }^{\#}$
}

\author{
Comparative hematological and pathological study of inoculated pigs with a field \\ isolate and an ATCC serotype 5 of Actinobacillus pleuropneumoniae \\ D Muñoz ${ }^{\mathrm{a}}$, A Ruiz ${ }^{\mathrm{a}}$, M González ${ }^{\mathrm{a}}$, A Islas ${ }^{\mathrm{a}}, \mathrm{N}$ Díaz $^{\mathrm{c}}, \mathrm{M}_{\text {Quezada }}{ }^{\mathrm{a}}$ \\ ${ }^{a}$ Facultad de Ciencias Veterinarias, Universidad de Concepción, Chillán, Chile. \\ bPrograma de Doctorado en Ciencias Agropecuarias, Universidad de Concepción, Chillán, Chile. \\ 'Departamento de Laboratorios y Estaciones Cuarentenarias Agrícolas y Pecuarias, \\ Complejo Lo Aguirre, Servicio Agrícola y Ganadero, Santiago, Chile.
}

\begin{abstract}
SUMMARY
An experimental inoculation of Actinobacillus pleuropneumoniae (App) was carried out with a field isolate and an ATCC serotype 5. Three groups of 15 pigs each were used. Group 1 (G1) was the control group inoculated with sterile media, Group 2 was inoculated with the serotype 5 ATCC, and Group 3 (G3) was inoculated with a field isolate (418/07). The results showed statistically significant differences $(\mathrm{P} \leq 0.05)$ in the total leukocytes count between G1 v/s G2 and G1 v/s G3. The total macroscopic lung lesions scores were statistically different among the 3 groups $(\mathrm{P} \leq 0.05)$. However, statistical difference was found only between G1 and G3 in the histopathological lung lesions $(\mathrm{P} \leq 0.05)$. This work shows a clear difference in the hematological changes and the macroscopic and histopathological lesions between the serotype 5 ATCC and the field isolate. These facts suggest a higher virulence and pathogenicity of the national isolate. The serotypification of this App national isolate will be done in the near future.
\end{abstract}

Palabras clave: Actinobacillus pleuropneumoniae, hematología, patología.

Key words: Actinobacillus pleuropneumoniae, hematology, pathology.

\section{INTRODUCCIÓN}

Actinobacillus pleuropneumoniae (App) es una bacteria cocobacilar, Gram negativa, encapsulada, hemolítica y anaerobia facultativa de la familia Pasteurellaceae (Vadillo y col 2002) y agente etiológico de la pleuroneumonía contagiosa porcina (PCP), una de las enfermedades bacterianas más importantes del complejo respiratorio porcino (Losinger 2005). La transmisión de la enfermedad ocurre por la introducción de animales portadores, que diseminan App a través del aire, ya sea por gotas de aerosol o por el contacto directo entre los cerdos (Jacobsen y col 2005).

En cuanto a la patogenicidad y virulencia de App, se ha observado que los serotipos $1,5,9$ y 11 son los más virulentos (Haesebrouck y col 1997). Sin embargo, se debe señalar que cualquier serotipo puede causar cuadros sobreagudos, dependiendo del perfil de expresión y secreción de toxinas Apx (I, II, III, IV), el cual es distinto en cada serotipo (Dreyfus y col 2004), existiendo así una asociación entre el serotipo y los brotes que se presentan en un plantel porcino (Gottschalk 1998).

En cuanto a las alteraciones hematológicas observadas en cerdos con cuadro agudo o crónico de PCP, Kiorpes y col (1990) detallan cambios drásticos en el leucograma,

\footnotetext{
Aceptado: 08.07.2009.

\# Proyecto FONDECYT No 1070459.

Av. Vicente Méndez 595, Chillán, Chile; aruiz@udec.cl
}

con un rápido descenso de los leucocitos totales en los cuadros sobreagudos; sin embargo, hay escasas referencias respecto a los cambios hematológicos.

Por otro lado, las lesiones típicas de PCP se presentan generalmente en la cavidad torácica, limitada a los pulmones y serosas. Los cuadros agudos se caracterizan por la presencia de lesiones fibrinosas y necróticas demarcadas en los lóbulos diafragmáticos, cardíacos y apicales (Buret y col 2004). También se aprecian septos interlobulillares engrosados y edematosos, en conjunto con zonas necróticas oscuras y consolidadas. Además, comúnmente se observa una pleuritis fibrinosa, especialmente relacionada con las zonas neumónicas (Dubreuil y col 2000). En los cuadros crónicos de PCP hay zonas de necrosis y secuestros pulmonares, rodeados por una gruesa capa de tejido de granulación (Liggett y col 1987). Histopatológicamente se observan zonas de necrosis pulmonar de manera irregular, demarcada por un intenso infiltrado celular mononuclear. También es frecuente encontrar trombosis en vasos sanguíneos de mediano calibre y microcolonias de bacterias en los alvéolos (Wang y col 2001).

En Chile existen escasos reportes sobre la enfermedad; uno de ellos describe un brote causado por los serotipos 1 y 5 (Olivares y Morgado 1988), dos de los serotipos más patógenos de App (Chiers 2003), mientras que Sánchez y col (1986) aislaron App de un brote en un plantel industrial de la Región Metropolitana, que cursó con una morbilidad de $10 \%$ y $15 \%$ en recría y crianza-engorda y, 
una mortalidad de $2,6 \%, 0,5 \%$ y $1,1 \%$ en recría, crianza y engorda, respectivamente. Recientemente, Muñoz y col (2008) realizaron un estudio serológico, utilizando ELISA indirecto, en planteles porcinos de la zona central de Chile, determinando una prevalencia aparente de $10,48 \%$ y prevalencia verdadera de entre $9,6 \%$ y $10,67 \%$, mediante dos métodos estadísticos. Por lo tanto, tomando en cuenta que la PCP causa brotes y cuadros endémicos, con las consiguientes pérdidas económicas, es esencial iniciar estudios nacionales en cuanto a patogenicidad, prevalencia y serotipos actuantes en los planteles nacionales, lo cual incidirá directamente en el desarrollo de la industria porcina nacional.

El presente estudio compara las diferencias entre la cepa estándar ATCC (American Type Culture Collection), serotipo 5 de A. pleuropneumoniae y un aislado nacional de campo (418/07) sobre los parámetros hematológicos y lesiones macroscópicas e histopatológicas con el fin de conocer la patogenicidad de este aislado para mejorar las medidas de control y diagnóstico de la enfermedad.

\section{MATERIAL Y MÉTODOS}

\section{AISLADOS BACTERIANOS}

En este trabajo se utilizaron el serotipo 5 ATCC de App, ya descrito para nuestro país, y un aislado de campo (418/07), perteneciente al Cepario del Laboratorio de Patología Porcina de la Facultad de Ciencias Veterinarias de la Universidad de Concepción, y que fue aislado de pulmones de cerdos que cursaron con PCP aguda en una granja de zona central de Chile durante el año 2007.

\section{SITIO DE EXPERIMENTACIÓN Y MEDIDAS DE BIOSEGURIDAD}

La experiencia se llevó a cabo en dependencias del Departamento de Laboratorios y Estaciones Cuarentenarias Agrícolas y Pecuarias, Complejo Lo Aguirre, pertenecientes al Servicio Agrícola y Ganadero (SAG), el cual dispone de una Unidad de Control de Productos Biológicos, constituida por tres dependencias totalmente aisladas unas de otras (unidad experimental 1, 2 y 3 ), cada una de las cuales cuenta con ducha esclusa independiente.

Cada unidad experimental tiene cuatro corrales para cerdos con piso elevado de concreto parcialmente cubierto con piso plástico ranurado, bebederos automáticos, ventilación mecánica, temperatura controlada y equipados con filtros de aire HEPA. Previo al inicio de la experiencia, las unidades experimentales fueron lavadas, desinfectadas (Ortofenilfenol LY-7 al 2\%, Productos Químicos Beryl Ltda.) y fumigadas (Ciperkill@, Anasac) con el fin de evitar moscas y mosquitos.

A la llegada de los animales estos fueron identificados y separados en grupos al azar en las diferentes unidades experimentales. El alimento fue formulado por la misma empresa porcina proveedora de los cerdos, sin antibióticos, dejándose este separado en las respectivas salas, y suministrándose dos veces al día.

Para evitar la transmisión de la enfermedad entre los grupos por razones de manejo, cada unidad se consideró como una unidad epidemiológica independiente, con personal entrenado y exclusivo para aseo y alimentación de los cerdos en cada una de ellas. Previo al ingreso, el personal debía ducharse y equiparse con material desechable (buzos, cofias, mascarillas y guantes), botas limpias y al ingreso y salida de las salas tenían que pasar a través de un pediluvio.

\section{ANIMALES DE EXPERIMENTACIÓN Y DISEÑO EXPERIMENTAL}

Se utilizaron 45 cerdos híbridos LWxL, de ocho semanas de edad, obtenidos de una granja monitoreada periódicamente para PCP, no existiendo cuadros clinicos, ni lesiones asociadas a App en los últimos cinco años, y seronegativos a App, a través de serología (IDEXX Chekit-APP-ApxIV, Laboratorios Bommeli Diagnostics, Suiza), el cual tiene una especificidad del 99 al $100 \%$ y una sensibilidad del 95 al $100 \%$. Los cerdos fueron divididos en tres grupos al azar, de 15 animales cada uno. A su llegada, se realizó un período de aclimatación de una semana, y se aplicaron medidas de bioseguridad y de manejo respetando el bienestar animal.

El diseño experimental y la distribución de los grupos fue la siguiente:

Grupo $1(G 1)$ : correspondió al grupo control $(\mathrm{n}=15)$, fueron inoculados con $2 \mathrm{ml}$ intranasal (IN) y $4 \mathrm{ml}$ intratraqueal (IT) mediante sonda fenestrada con una solución de medio de cultivo estéril. Grupo 2 (G2): los cerdos $(\mathrm{n}=15)$ fueron inoculados con $2 \mathrm{ml}$ IN y $4 \mathrm{ml}$ IT de una suspensión de bacterias en concentración $10^{9} \mathrm{UFC} / \mathrm{ml}$ de A. pleuropneumoniae serotipo 5 ATCC. Grupo 3 (G3): los cerdos de este grupo $(n=15)$ fueron inoculados por las mismas vías y dosis que G2 utilizando un aislado de campo (418/07) de A. pleuropneumoniae.

Para realizar la inoculación los animales fueron tranquilizados con acepromacina maleato $1,1 \mathrm{mg} / \mathrm{kg}$ intramuscular y anestesiados con xilacina al $2 \%$, en dosis de $2 \mathrm{mg} / \mathrm{kg}$ im (Centrovet) y ketamina al 5\% dosis $20 \mathrm{mg} / \mathrm{kg}$ im (Centrovet). Los cerdos de todos los grupos fueron observados diariamente para constatar signos clínicos y se les realizó control de temperatura rectal cada 24 horas.

\section{TOMA DE MUESTRAS ANTE MORTEM}

Todos los animales fueron muestreados en sus respectivas unidades. Se obtuvieron muestras de sangre $(5 \mathrm{ml})$ con anticoagulante para hemograma y sin anticoagulante para la prueba de ELISA a los 0, 1, 3, 5, 7 y 14 días posinoculación (dpi) mediante una punción de la vena cava craneal, utilizando tubos de 5 y $10 \mathrm{ml}$ 
respectivamente (Vacutainer ${ }^{\circledR}$; Becton Dickinson Vacutainer System, Becton Dickinson and Company, Rutherford, NJ, USA).

\section{EUTANASIA}

Posterior a la toma de muestras, se sacrificaron tres cerdos de cada grupo a 1, 3, 5, 7 y 14 dpi. Previo a realizar la eutanasia los animales se sedaron con acepromacina maleato $1,1 \mathrm{mg} / \mathrm{kg}$ por vía intramuscular y luego sacrificados por una sobredosis de tiopental sódico intravenoso al 10\% (50 mg/kg) (Laboratorio Bestpharma S.A., Santiago, Chile).

\section{NECROPSIA Y RECOLECCIÓN DE MUESTRAS POST MORTEM} PARA ESTUDIOS COMPLEMENTARIOS

En la necropsia se analizó la distribución y extensión de las lesiones en los pulmones (Straw y col 2002) y se tomaron muestras de pulmón para cultivo microbiológico, las que se depositaron en bolsas estériles, debidamente rotuladas y refrigeradas; para histopatología se tomaron muestras de tonsila, nódulo linfático mediastínico y pulmón; de este último tejido se procedió a laminar tres muestras: una con lesiones evidentes y dos del límite de la lesión. Todas las muestras fueron fijadas en formol tamponado al $10 \%$ por 24 horas.

\section{PROCESAMIENTO Y ANÁLISIS DE LAS MUESTRAS}

Muestras para hematología y ELISA. Las muestras de sangre para hematología fueron refrigeradas y trasladadas al laboratorio clínico, donde se realizaron los hemogramas utilizando un contador hematológico Hycel Diagnostics, Celly. El recuento diferencial de leucocitos fue obtenido a través de los métodos convencionales descritos por Feldman y col (2000).

Las muestras de sangre para ELISA, una vez coaguladas se centrifugaron (Centrifuga Hermle LaborTechnik) por 10 minutos a $581 \mathrm{~g}$ para la extracción del suero, los que posteriormente fueron alicuotados y congelados a $-20{ }^{\circ} \mathrm{C}$ hasta su procesamiento para la identificación de anticuerpos contra Apx IV por ELISA (IDEXX ChekitAPP-Apx IV, Laboratorios Bommeli Diagnostics, Suiza) de acuerdo a lo descrito por Andreasen y col (2000). Cuando el valor OD obtenido de la muestra arrojó un valor $\mathrm{S} / \mathrm{P}$ menor a 0,3 se consideró negativo; valores entre 0,3 y 0,4 se consideraron sospechosos y valores sobre 0,4 como positivos.

Cultivo bacteriano. A cada bolsa con muestras de pulmón se le añadieron $10 \mathrm{ml}$ de suero fisiológico $(0,85 \% \mathrm{NaCl})$ estéril. Posteriormente, el tejido se maceró en un Stomacher 400 (Seward, Laboratory Blender, England). De cada muestra se extrajo mediante un asa metálica estéril aproximadamente $100 \mu \mathrm{l}$ para siembra en microplacas Petri, con agar PPLO a una concentración de $20 \mu \mathrm{g} / \mathrm{ml}$ (Difco, frasco de $500 \mathrm{~g}$, Becton Dickinson, USA), que fue suplementado con nicotinamida adenina dinucleótido (NAD) al 0,01\% (Fisher Scientific), además de $16 \mu \mathrm{g} /$ $\mathrm{ml}$ de espectinomicina y $60 \mu \mathrm{g} / \mathrm{ml}$ de bacitracina como inhibidores de flora contaminante. Todos los cultivos de App fueron mantenidos a una atmósfera de 5-10\% de $\mathrm{CO}_{2}$ a $37^{\circ} \mathrm{C}$, observándolos cada $12 \mathrm{~h}$ hasta visualizar pequeñas colonias mucoides $(1 \mathrm{~mm})$. El primer paso para la identificación de App se realizó aplicando el método Gram. Las colonias que resultaron Gram negativas pasaron a una batería bioquímica, que consistió en la reacción del fenómeno CAMP y de ureasa.

Histopatología. Las muestras fijadas en formol tamponado al $10 \%$ fueron incluidas en parafina utilizando un procesador de tejidos Shandon Citadel 1000 y un dispensador de parafina Microm AP280. De los bloques de parafina resultantes se realizaron cortes finos de $4 \mu \mathrm{m}$, los que fueron teñidos con hematoxilina y eosina y observados en un fotomicroscopio Carl Zeiss, Modelo Axioskop 40, provisto de cámara digital. Las imágenes fueron capturadas y procesadas utilizando el software Zeiss Axiovison Rel. 4.6, con el programa "Macro" diseñado para este fin (Reichman y Cía. Ltda., Chile).

\section{ANÁLISIS ESTADÍSTICO}

Para el análisis de hemogramas se aplicó un análisis de varianza para muestras independientes utilizando el software estadístico Primer of Biostatistics: The Program, versión 5.0 para Windows (McGraw-Hill Inc. Washington D.C., USA, Glantz, 2005).

Las lesiones macroscópicas fueron ponderadas en porcentajes de tejido afectado en cada lóbulo de los pulmones y la suma correspondió al "score" de cada cerdo. Finalmente se compararon los tres grupos entre sí para determinar si existían diferencias estadísticas, en cuanto al grado de lesión registrada en los distintos días de sacrificio de los cerdos; además se comparó el grado de lesión entre los distintos lóbulos pulmonares. Para determinar estas diferencias se utilizó la prueba de "t" para muestras independientes. Las lesiones microscópicas se evaluaron semicuantitativamente, subdividiendo estas en: (-): ausencia de lesiones; $(+)$ : lesión leve; $(++)$ : moderada, $(+++)$ : intensa. Posteriormente a cada gradación cualitativa se le designó un número: "0" para la ausencia de lesiones, "1", "2" para las moderadas y lesiones leves y "3" para las lesiones intensas. Así de esta manera se aplicó el test no paramétrico de Kruskal-Wallis para determinar diferencias estadísticas entre G1, G2 y G3. Lo anterior se realizó a través del software estadístico "Statistica 7.0" (Statsoft Inc, Tulsa, OK, USA). 


\section{RESULTADOS}

\section{ASPECTOS CLÍNICOS Y HEMATOLÓGICOS}

Signos clínicos. Los animales de G1 no manifestaron síntomas, ni signos clínicos de PCP, con una temperatura promedio de $38,7^{\circ} \mathrm{C}$. Los cerdos de $\mathrm{G} 2$ presentaron signos y sintomatología respiratoria de intensidad leve a severa (postración, inapetencia y tos). La temperatura promedio posinoculación se elevó en más de 1 grado, pasando de 38,3 a $39,7^{\circ} \mathrm{C}$ a $1 \mathrm{dpi}$, y se mantuvo alta hasta los $13 \mathrm{dpi}$, bajando a $38,7^{\circ} \mathrm{C}$ a los $14 \mathrm{dpi}$. Los animales de $\mathrm{G} 3$ tuvieron manifestaciones más exacerbadas, compatibles con un cuadro de PCP desde 1 dpi, caracterizada por respiración abdominal, tos, inapetencia completa, cianosis de la piel y fiebre, ocurriendo la muerte de dos animales a $1 \mathrm{dpi}$. La temperatura media de este grupo durante las dos semanas fue de $39,4^{\circ} \mathrm{C}$, con un pico de $40^{\circ} \mathrm{C}$ a 1 dpi.

Seroconversión. Todos los sueros de los cerdos que fueron muestreados a los 0 dpi (G1, G2 y G3) resultaron negativos al ELISA, mientras que a los $7 \mathrm{dpi}$, un animal del grupo G3 fue sospechoso. Finalmente, a los 14 dpi, los tres cerdos de G2 seroconvirtieron, mientras que de los dos animales sobrevivientes de G3, uno de ellos fue positivo y el otro sospechoso. Ningún animal de G1 seroconvirtió a los 7 y 14 dpi.

Cambios hematológicos. El recuento total de leucocitos de los tres grupos de animales a los 0 dpi evidenció que todos ellos se encontraban dentro de valores normales para la especie; sin embargo, desde 1 dpi comenzaron a variar aquellos valores entre el grupo de animales controles y los inoculados, debido al cuadro agudo de PCP (cuadro 1). A 1 dpi los cerdos de $\mathrm{G} 2(\mathrm{n}=15)$ presentaron leucocitosis, que en promedio sobrepasó los $25.000 \pm 8.501$ leucocitos/ $\mu$; sin embargo, el grupo G1 y el G3 sólo mostraron un leve aumento (G1: $20.313 \pm 4.287$;
G3: 21.186 \pm 8.047). A los 3, 5, 7 y 14 dpi, G2 mostró un aumento moderado del recuento de leucocitos, mientras que G3 mostró un aumento constante, hasta sobrepasar $40.000 \pm 27.082$ leucocitos/ $\mu \mathrm{l}$ a los $14 \mathrm{dpi}$. Lo anterior demostró una diferencia estadística significativa $(\mathrm{P} \leq 0,05)$ entre G1 y G2, así como también entre G1 y G3 en el recuento de leucocitos totales, no así entre G2 y G3.

En cuanto al recuento diferencial de leucocitos, se observó una diferencia leve, no estadísticamente significativa, en los valores de linfocitos y neutrófilos entre el grupo control y los dos grupos experimentales ( $\mathrm{P} \geq 0,05)$, la que se debió a un aumento de neutrófilos inmaduros a $1 \mathrm{dpi}(\mathrm{P} \geq 0,05)$. Además estos neutrófilos presentaron características de cambios tóxicos como: citoplasma vacuolado, basófilo y algunos con cuerpos de Döhle ocasionales. A los 7 dpi se observó una marcada neutrofilia en los grupos $\mathrm{G} 2$ y G3, en conjunto con una linfopenia; sin embargo, no se evidenció una diferencia estadística significativa entre los grupos 2 y 3 $(P \geq 0,05)$. Finalmente a los 14 dpi esta tendencia se revirtió, aumentando los linfocitos y disminuyendo los neutrófilos. En cuanto a los monocitos y eosinófilos, éstos se mantuvieron inalterables durante toda la experiencia.

\section{ASPECTOS PATOLÓGICOS}

Aislamiento bacteriano. A partir de las muestras de pulmón ( $\mathrm{n}=15$ ) obtenidas de los cerdos de G1 necropsiados durante la experiencia, el $100 \%$ de ellas resultaron negativas para el aislamiento A. pleuropneumoniae (App). En G2 $(\mathrm{n}=15)$ se reaisló App en siete muestras de pulmón, correspondientes al $46,7 \%$ de los animales, mientras que en G3 $(\mathrm{n}=15)$ el 66,7\% (10/15) de las muestras de pulmón arrojaron resultados positivos al cultivo de App.

\section{LESIONES MACROSCÓPICAS}

Grupo control G1. Ninguno de los animales de este grupo presentó lesiones neumónicas o lesiones compatibles con

Cuadro 1. Promedios de leucocitos $(\mu \mathrm{l})$ y desviación estándar de cerdos experimentalmente inoculados con una cepa ATCC 5 de App y un aislado de campo, agrupados según tratamiento. G1: grupo control, G2: grupo inoculado con cepa ATCC serotipo 5, G3: grupo inoculado con aislado de campo.

Leukocytes mean $(\mu \mathrm{l})$ and standard deviation of pigs experimentally inoculated with an App ATCC 5 serotype and a field isolated, grouped according to treatment. G1: control group, G2: group inoculated with serotype 5 ATCC, G3: Group inoculated with field isolated.

\begin{tabular}{lcccrrrr}
\hline \multicolumn{7}{c}{ Leucocitos por microlitro $(\mu \mathrm{l})$} \\
\hline
\end{tabular}


infección por App durante los días de sacrificio (1, 3, 5, 7 y 14 dpi), por lo que su "score" de lesiones pulmonares fue cero durante todo el periodo (cuadro 2). Los nódulos linfáticos mediastínicos presentaron tamaño pequeño y aspecto normal.

Grupo G2 inoculado con serotipo 5 ATCC. Las lesiones pulmonares observadas en el grupo G2 se hicieron más evidentes a los 3 dpi, llegando a su mayor grado de lesión a los $5 \mathrm{dpi}$; los cerdos afectados presentaron lesiones típicas de una infección por App, con focos neumónicohemorrágicos y necróticos, pleuritis moderada y adherencias leves entre las pleuras. A los 7 dpi las lesiones fueron más organizadas y de un menor tamaño. A los 14 dpi las lesiones eran pequeñas y con una fibrosis intensa y adherencias pleurales (figura 1A).

El promedio de lesiones pulmonares $(\mathrm{n}=15)$ de los animales de este grupo fue de un 7,7\%, observándose el mayor "score" a los 5 dpi, el cual alcanzó a $21,75 \%$. Los nódulos linfáticos mediastínicos se observaron con un leve aumento de tamaño y congestivos.

Grupo G3 inoculado con el aislado de campo. Las lesiones observadas en G3 fueron sobreagudas a 1 dpi, apreciándose en los pulmones extensas zonas de aspecto hemorrágico y áreas de necrosis. Además los pulmones estaban escasamente colapsados, con edema, septos interlobulillares distendidos y presencia de líquido sanguinolento en la cavidad pleural. A los 3 y 5 dpi las lesiones pulmonares tenían mayor organización y delimitación; sin embargo, seguían siendo de gran intensidad, asociadas con pleuritis serofibrinosa extensa (figura 1B). A los 7 dpi había lesiones neumónicas focales, necróticas y firmes y pleuritis extensas. A los 14 dpi fue más frecuente encontrar lesiones encapsuladas (secuestros) y adherencias pleurales bien

Cuadro 2. Promedio porcentual de las lesiones pulmonares observadas en cerdos experimentalmente inoculados con una cepa de App, agrupados según tratamiento durante los diferentes periodos de necropsia $(1,3,5,7,14 \mathrm{dpi})$. G1: grupo control, G2: grupo inoculado con cepa ATCC serotipos 5, G3: grupo inoculado con aislado de campo. dpi: días posinoculación.

Mean of the percentage of lungs lesions observed in pigs experimentally inoculated with a strain of $A p p$, grouped according to treatment during different periods of necropsy (1, 3, 5, 7, 14 dpi). G1: control group, G2: group inoculated with serotypes 5 ATCC, G3: Group inoculated with field isolated. dpi: days post inoculation.

\begin{tabular}{cccccc}
\hline \multicolumn{5}{c}{ Promedios de lesiones pulmonares } \\
por grupo en los diferentes días de eutanasia \\
\hline & 1 dpi & 3 dpi & 5 dpi & 7 dpi & 14 dpi \\
\hline G1 & $0^{\mathrm{b}}$ & $0^{\mathrm{b}}$ & $0^{\mathrm{b}}$ & $0^{\mathrm{b}}$ & $0^{\mathrm{b}}$ \\
$\mathrm{G} 2$ & $0^{\mathrm{b}}$ & $4,75^{\mathrm{bc}}$ & $21,75^{\mathrm{b}}$ & $7^{\mathrm{b}}$ & $5^{\mathrm{c}}$ \\
$\mathrm{G} 3$ & $35,3^{\mathrm{c}}$ & $50,7^{\mathrm{c}}$ & $40^{\mathrm{b}}$ & $37,5^{\mathrm{b}}$ & $23,5^{\mathrm{c}}$ \\
\hline
\end{tabular}

a, b, c Valores con diferentes letras por columna en superíndice indican diferencias estadísticamente significativas por medio de la prueba de t para muestras independientes.

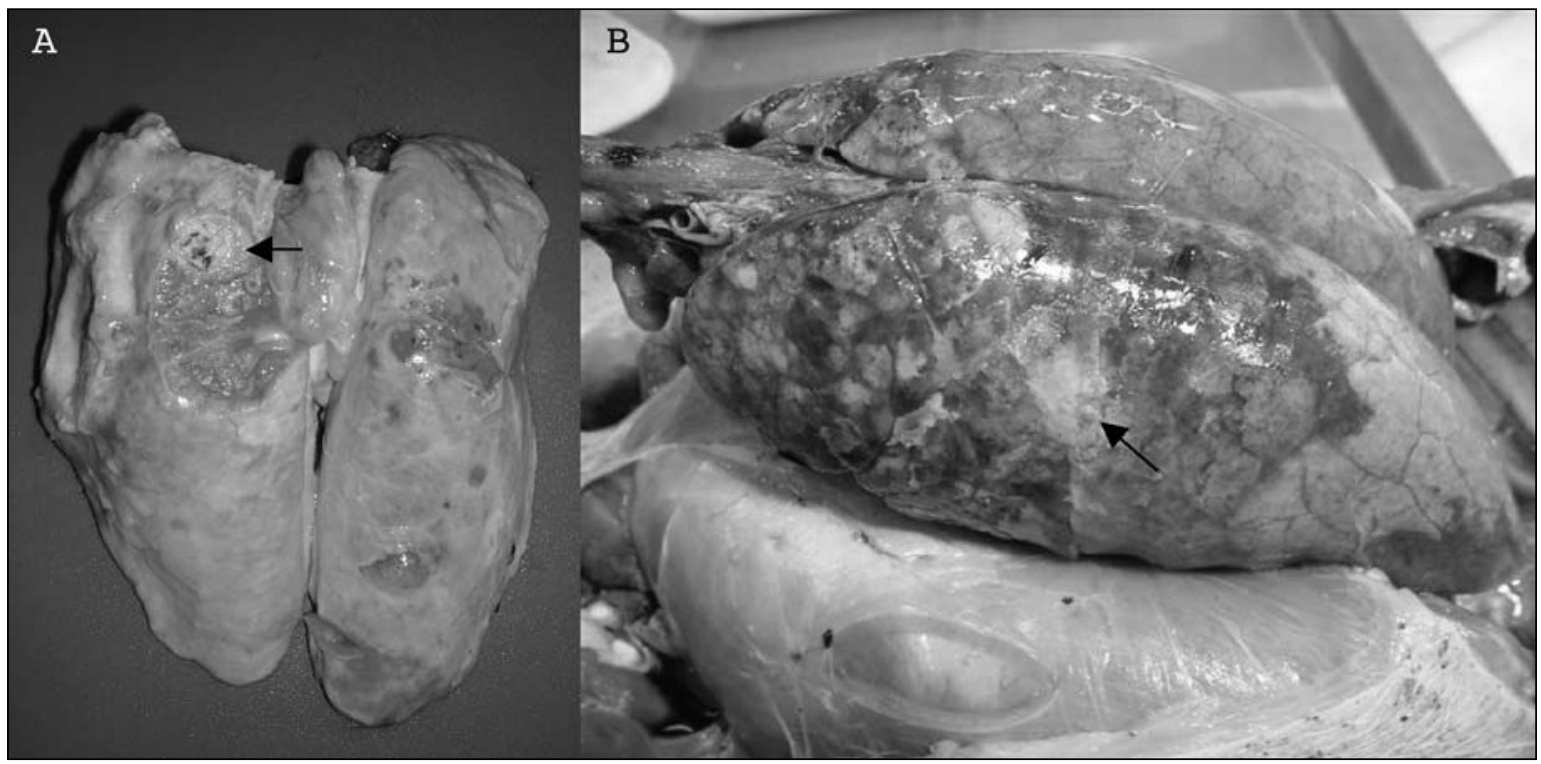

Figura 1. Pulmones de cerdos experimentalmente inoculados con App. A: Foco neumónico consolidado (flecha) en lóbulo cardiaco (animal de G2, 14 dpi. crotal 39). B: Focos neumónicos en lóbulo apical, cardiaco y parte dorsal del lóbulo caudal del pulmón izquierdo. Además se aprecia intenso edema intersticial y pleuritis severa (flecha) (animal de G3, 5 dpi. crotal 24).

Lungs of experimentally inoculated pigs with App. A: Consolidate pneumonic focal lesion (arrow) in cardiac lobe (animal from G2, 14 dpi. eartag 39). B: Pneumonic lesion in apical, cardiac and dorsal part of caudal lobes of the left lung. In addition there is an intense edema and severe pleuritis (arrow) (animal from G3, 5 dpi. eartag 24). 
consolidadas. Los nódulos linfáticos mediastínicos se observaron aumentados de volumen, inicialmente muy congestivos, edematosos en los cuadros agudos de 3 y 5 dpi y aumentados de tamaño a los 14 dpi.

El promedio de lesiones pulmonares de G3 fue de 37,4\% $(n=15)$, lo que convierte a este grupo en el más afectado. Al analizar los tres grupos y comparar sus "scores" totales de lesiones pulmonares, sin considerar los días de sacrificio, se aprecian diferencias estadísticamente significativas $(\mathrm{P} \leq 0,05)$ entre los tres grupos de estudio. Al comparar las medias de porcentajes de lesiones pulmonares entre los distintos grupos a un mismo día de sacrificio se observó una diferencia significativa ( $\mathrm{P} \leq 0,05 \%)$ entre $\mathrm{G} 1$ y G3, así como también entre G2 y G3, no así entre G1 y G2 en 1 dpi. En los siguientes días de necropsia se apreciaron diferencias estadísticas en 3 dpi sólo entre G1 y G3, mientras que a los 14 dpi se observó diferencia entre G1 v/s G2 y G1 v/s G3 (cuadro 2).

\section{LESIONES HISTOLÓGICAS}

Grupo control G1. En el grupo control no se observaron lesiones neumónicas, ni lesiones compatibles con infección con App en ninguno de los cerdos. La tonsila presentó detritus con exudado e hiperplasia del tejido linfoide en un animal a $1 \mathrm{dpi}$. Los nódulos linfáticos no presentaron evidencias de necrosis, apoptosis o activación del tejido linfoide.

Grupo G2 inoculado con serotipo 5 ATCC. Los cerdos presentaron lesiones características de App desde 1 dpi, observándose edema alveolar, aumento de macrófagos alveolares pulmonares (MAPs) y presencia de detritus en los bronquios y bronquiolos. A los 3 dpi había neumonías leves y microtrombosis de vasos pequeños. A los 5 dpi se observó microtrombosis, áreas de necrosis y zonas de neumonías extensas y severas con MAPs, detritus y fibrina en los alvéolos (figura 2A). Los septos interlobulillares tenían vasos linfáticos distendidos y había depósitos de fibrina e infiltrados de leucocitos en ellos. A los 7 y 14 dpi las lesiones disminuyeron en intensidad, observándose exudado en los alvéolos de carácter leve a moderado. Las zonas de necrosis, asociadas a vasos trombosados, tenían un fuerte infiltrado leucocitario, con detritus y neoformación fibrosa en la zona periférica. Por otra parte, la pleura presentaba lesiones más intensas a los $5 \mathrm{dpi}$, disminuyendo progresivamente a los 7 y 14 dpi. En las tonsilas se encontraron detritus en criptas, con presencia de colonias bacterianas y necrosis aisladas del tejido linfoide, sin observarse diferencias importantes en relación a los días de sacrificio de los animales. En el nódulo linfático mediastínico se encontraron principalmente necrosis aislada en el tejido linfoide e hiperplasia de los folículos a los 5 y 7 dpi.

Grupo G3 inoculado con el aislado de campo. En G3 las lesiones pulmonares fueron de gran severidad desde el inicio y con características de una infección por App. En los animales sacrificados a los 1 y 3 dpi se apreciaron hemorragias intensas, edema, exudado y colonias bacterianas en los alvéolos. Los bronquiolos y bronquios presentaron exudado conformado principalmente por macrófagos de citoplasma espumoso (activados) y neutrófilos. En los

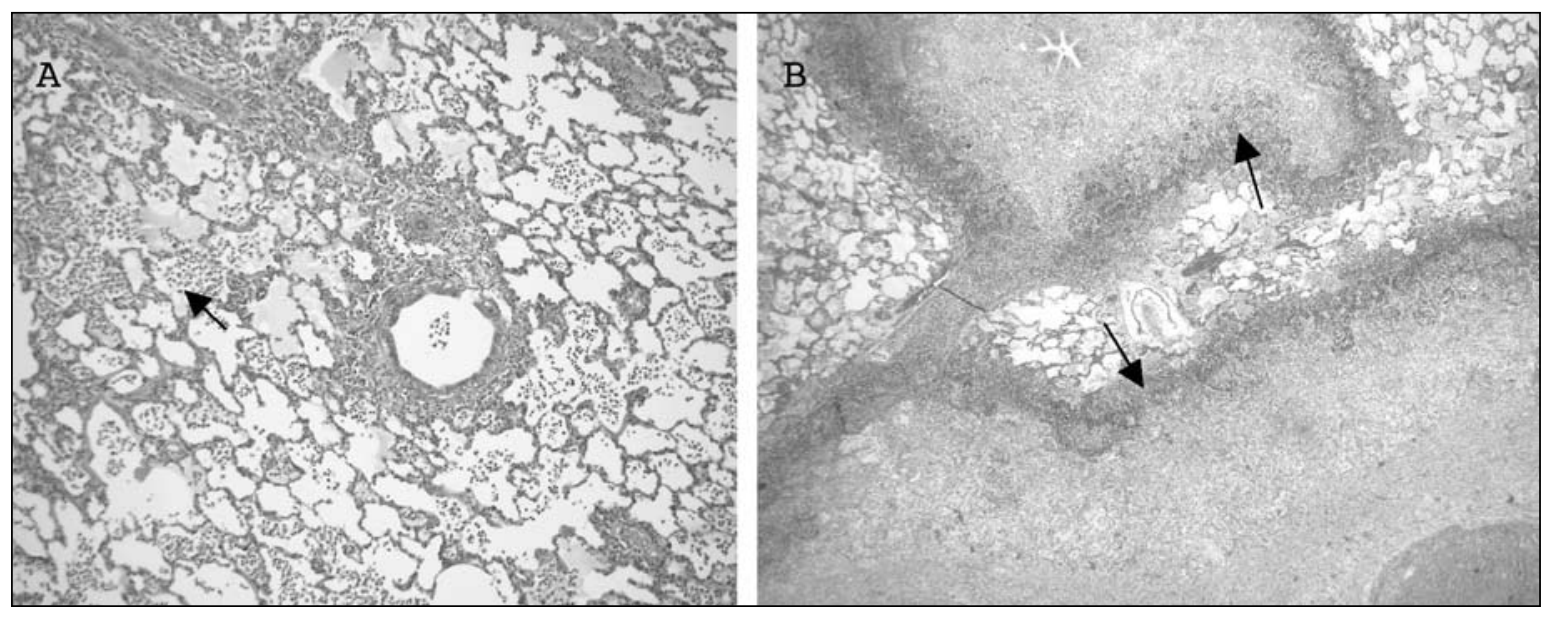

Figura 2. Cortes histológicos de pulmones de cerdos experimentalmente inoculados con App. A: Se aprecia un infiltrado leucocitario alveolar compuesto por macrófagos activados y polimorfonucleares (PMNs)(flecha), y edema alveolar leve (cerdo de G2, 5 dpi. crotal 11. H y E; aumento 100X). B: Se aprecia un intenso infiltrado leucocitario alveolar rodeado por un halo inflamatorio y la neoformación de tejido fibroso en la periferia (secuestro) (flechas) (cerdo G3, 5 dpi. crotal 24. H y E; aumento 32X).

Lung histology of experimentally inoculated pigs with App. A: Wide leukocytes alveolar infiltrates composed of activated macrophages and polymorphonuclear cells (arrow) and a mild alveolar edema (pig from G2, 5 dpi. eartag 11. H-E; 100X). B: Severe leukocytes alveolar infiltrates, surrounded by an inflammatory halo and neoformation of fibrous tissue in the periphery (secuestrum) (arrows) (pig from G3, 5 dpi. eartag 24. H-E; 32X). 
septos interlobulillares también se observaron infiltrados leucocitarios, vasos sanguíneos congestivos y/o trombosados, hemorragias y dilatación de vasos linfáticos. A los 5 y 7 dpi estas lesiones estaban más organizadas y con exudado importante dentro de los alvéolos, bronquiolos y bronquios. Además, se observaron zonas de necrosis, con organización de tejido inflamatorio periférico (secuestros de tejido necrótico) (figura 2B). A los 14 dpi las lesiones necróticas estaban bien consolidadas y fibrosadas periféricamente. La pleura presentó un grado de pleuritis intenso a los 3 dpi, mientras que a los 7 y 14 dpi las lesiones se tornaron más crónicas y mejor organizadas. Las tonsilas tenían detritus y colonias bacterianas durante toda la experiencia y necrosis aisladas del tejido linfoide de forma moderada a intensa. El nódulo linfático mediastínico presentó necrosis linfoides aisladas y/o focales de moderadas a intensas a $1 \mathrm{dpi}$, disminuyendo progresivamente hasta los 14 dpi.

Comparación estadística de las lesiones histopatológicas entre los grupos de cerdos inoculados (G1, G2 y G3). Al comparar los grupos G1, G2, y G3, las tonsilas tenían una diferencia estadística entre el G1 y G3 (P $\leq 0,05)$. El análisis del nódulo linfático mediastínico mostró diferencia estadística significativa sólo entre G1 y G2 ( $\mathrm{P} \leq 0,05)$, no así entre el grupo G2 y G3, donde no se detectó tal diferencia en las lesiones histopatológicas. Finalmente, el análisis de las lesiones pulmonares mostró diferencias estadísticas significativas entre G1 y G3 (P $\leq 0,05)$.

\section{DISCUSIÓN}

Clínicamente, los cerdos de los grupos inoculados con App (G2 y G3) hicieron un cuadro clínico de PCP, ocurriendo una sintomatología más evidente en los cerdos inoculados con el aislado de campo, que presentaron un cuadro febril desde 1 dpi hasta los 9 dpi, concordando con lo descrito por Maes y col (2001), así como un cuadro sobreagudo de la enfermedad que causó la muerte de dos animales al 1 dpi. Este aspecto es coincidente con lo descrito por Dubreuil y col (2000) y Straw y col (2002), quienes encontraron un cuadro febril intenso inicial, debido a que App puede expresar y secretar un perfil determinado de citotoxinas, ya sea Apx I, II o III, mientras que todos los serotipos secretan la toxina Apx IV (Koyama y col 2007).

La evaluación de la infección de los animales se realizó mediante dos técnicas: la prueba de ELISA en los animales vivos y el aislamiento microbiológico del agente en los pulmones de los cerdos al momento de realizar la necropsia. En el primer caso, el test de ELISA resultó negativo para todos los cerdos de G1, G2 y G3 antes de ser inoculados. Posterior a la inoculación, se observó seroconversión a los 14 dpi. Aun así, un 37,5\% de los animales se mantuvo negativo al test de ELISA ( $\mathrm{n}=8$ animales). No obstante, dentro de este porcentaje se incluyen los tres animales de G1 a los 14 dpi, los cuales debían ser negativos a la prueba, mientras que los cinco restantes, de G2 y G3, cuatro seroconvirtieron y uno arrojó un resultado de sospechoso, lo que avala la alta especificidad y sensibilidad de la prueba de ELISA creada por Dreyfus y col (2004). Por otra parte, el test indirectamente entrega información respecto al estado inmunitario del plantel de donde provenían los animales, ya que no había anticuerpos calostrales, ni anticuerpos circulantes en respuesta a la toxina Apx IV, recordando que el gen de esta exotoxina sólo se expresa in vivo. Para este trabajo, los animales fueron seleccionados de una granja libre de App y libres de anticuerpos calostrales, por lo que la seroconversión de ellos ocurrió de forma similar a la descrita por Straw (2002); sin embargo, un cerdo de G3 no seroconvirtió a los 14 dpi, lo que podría estar asociado a varias causas, dentro de las cuales la más plausible es que el cerdo no generó una respuesta inmunológica de tipo humoral acorde con la gravedad del cuadro clínico y lesiones observadas (Sánchez y col 2005). Este efecto se podría deber a una secreción de citocinas antiinflamatorias (IL-10) (Cho y col 2005).

Por otra parte, el aislamiento de App desde el pulmón permite constatar la infección en los animales; sin embargo, esta técnica no está exenta de dificultades, ya que el App tiene requerimientos especiales de cultivo como es un ambiente microaerofílico. En esta experiencia el aislamiento de App desde el pulmón fue de 46,7\% para G2 y 66,7\% para G3, utilizando medio PPLO suplementado con NAD e incubado con un $10 \%$ de $\mathrm{CO}_{2}$ a $37^{\circ} \mathrm{C}$. Según O’Reilly y Niven (2002), los mejores resultados se obtienen desde muestras de pulmón recolectadas durante la necropsia, que a pesar de las condiciones entregadas esta técnica sigue teniendo una baja sensibilidad, la cual según estudios de Fittipaldi y col (2003) es de un 17\%. Sin perjuicio de todo lo anterior, la imposibilidad de reaislar App de todos los cerdos inoculados pudo radicar en una baja carga bacteriana en el pulmón de algunos animales o la capacidad que tienen de eliminar un patógeno de su organismo a través de la acción del sistema inmunológico, principalmente de inmunidad tipo celular (Haesebrouck y col 1997), lo que puede estar relacionado con una mayor presencia de exudado leucocitario en los alvéolos a partir de los 5 dpi y hasta 14 dpi en G2 y durante toda la experiencia en $\mathrm{G} 3$.

Por otra parte, existen escasos trabajos sobre cambios hematológicos en el curso de la PCP. Los cambios hematológicos encontrados en el presente estudio son propios de un cuadro inflamatorio agudo y endotoxemia severa. Sin embargo, a diferencia de lo encontrado por Kiorpes y col (1989), en donde el nivel máximo de leucocitos se presentó justo en el momento en que se detectaron los signos clínicos y alza térmica de los animales en este estudio el aumento de leucocitos se observó dos semanas posterior a la inoculación, tanto en el grupo de cerdos inoculados con el serotipo 5 ATCC como en el grupo inoculado con el aislado de campo. Lo anterior pudiese deberse a la patogenicidad y virulencia más relevante 
del aislado nacional, en comparación con el serotipo 5 ATCC utilizado, lo que concuerda con lo expresado por Haesebrouck y col (1997) en su revisión. Los cambios en el recuento diferencial del leucograma también son consistentes con un cuadro agudo endotóxico. Al igual que lo descrito por Kiorpes y col (1990), se observó una disminución leve de los neutrófilos a 1 dpi y una disminución continua de la línea mononuclear hasta los $7 \mathrm{dpi}$, los cuales se encontrarían secuestrados a nivel pulmonar (Lumsden 2000). Un patrón similar en la dinámica del leucograma se ha observado en cerdos inoculados experimentalmente con endotoxina vía endotraqueal, a una concentración de $0,1 \mu \mathrm{g} / \mathrm{ml}$ en $10 \mathrm{ml}$ de solución salina (Fenwick y col 1986). Así, la leucocitosis observada en este estudio se debería principalmente a un aumento de neutrófilos inmaduros, seguido por un aumento de monocitos, los cuales comenzaron a repuntar posterior a 7 dpi. No obstante, en otro estudio realizado por Kiorpes y col (1990) se demostró que en aquellos cerdos que sufrieron los cuadros más agudos se presentó una disminución significativa de toda la línea leucocitaria a las cuatro horas posinoculación, y que continuó bajando hasta el deceso de los animales. En conclusión, los datos obtenidos en este estudio difieren en algunos aspectos con Kiorpes y col (1990), posiblemente por el uso de serotipos diferentes de App.

En cuanto a las lesiones macroscópicas, éstas fueron concordantes con los estudios realizados por otros autores (Dubreuil y col 2000, Buret y col 2004). Sin embargo, las lesiones observadas en G3 fueron más extensas y severas que las descritas por Buret y col (2004), por cuanto en algunos animales de G3, sacrificados a 1 dpi, había extensas lesiones de necrosis en el parénquima y algo similar se observó en un animal de G2 de 5 dpi, en donde gran parte del pulmón derecho presentaba lesiones de aspecto necrótico de coloración oscura. Al comparar las medias de las lesiones en los 15 cerdos de cada grupo sólo se observó diferencia estadística a 1 dpi, no así en los demás días de sacrificio. Lo anterior estaría relacionado a que las lesiones más agudas se observan posterior al primer día posinoculación, mientras que en 3 , 5,7 , y 14 dpi la respuesta orgánica redujo ostensiblemente las lesiones y el porcentaje de pulmón afectado, por lo que no se generaron diferencias estadísticas significativas para estos días posinoculación.

Por otro lado, las lesiones histopatológicas observadas fueron las típicas descritas para las infecciones producidas por App; sin embargo, como la inoculación se realizó en animales que provenían de una pirámide genética libre de anticuerpos contra App, las lesiones fueron mucho más prominentes que las descritas por Dubreuil y col (2000) en donde las hemorragias alveolares fueron más bien ocasionales, mientras que el intenso exudado leucocitario, microtrombosis y edema intersticial fueron las lesiones más comúnmente encontradas (Bertram 1988). En los casos sobreagudos, el exudado leucocitario estuvo compuesto principalmente por un reclutamiento intenso de polimorfonucleares (PMNs) y macrófagos activados, lo que ya ha sido descrito extensamente por Wang y col (2001). A medida que los cuadros evolucionaron, el contenido de macrófagos en los alvéolos aumentó, observándose en ellos citoplasma espumoso, propio de células con fagocitosis activa; conjuntamente con esto se observó un número moderado de linfocitos. Por otra parte, la delimitación inflamatoria del tejido necrótico constituyendo múltiples zonas de secuestros en los animales de 14 dpi corresponde a las descripciones de la enfermedad en la fase tardía (Straw y col 2002).

La observación de figuras de necrosis aisladas y apoptosis en el tejido linfoide asociado al sistema respiratorio (tonsila y nódulo linfático mediastínico), observadas con mayor frecuencia desde 5 a 14 dpi en G2 y durante toda la experiencia en G3 se debería a la expresión masiva de citocinas a nivel sistémico (Ciprián y col 2004).

En el presente estudio fue posible caracterizar las manifestaciones clínicas y lesionales de un aislado de campo de App, obtenido a partir de animales que cursaron con la enfermedad aguda en planteles productivos chilenos. Los resultados de este estudio son una valiosa información sobre la patogenia de la enfermadad, la cual fue evaluada a través del comportamiento de los parámetros hematólogicos y lesiones macroscópicas e histológicas. Lo anterior permitió concluir que este aislado de campo corresponde a un App patógeno, por cuanto manifestó lesiones más intensas que las descritas para el serotipo 5 ATCC, el cual ha sido caracterizado como uno de los más patógenos dentro de los 15 serotipos existentes (Sanford 1998). La caracterización de este aislado de campo, sobre el estudio de la respuesta inmunológica y la secreción de citocinas proinflamatorias, en conjunto con la cinética de excreción de App, serán otros importantes aspectos que ayudarán a comprender aún mejor la patogenia de la PCP y apoyarán las medidas de control de la enfermedad en la industria porcina nacional.

\section{RESUMEN}

\footnotetext{
Se realizó una inoculación experimental de A. pleuropneumoniae utilizando un aislado de campo y una cepa de referencia ATCC serotipo 5, para lo cual se utilizaron tres grupos de animales $(n=15$ para cada grupo). El grupo 1 (G1) fue inoculado con medio estéril, el grupo (G2) con serotipo 5 ATCC y el grupo 3 (G3) fue inoculado con un aislado de campo (418/07). Los resultados mostraron diferencias significativas $(\mathrm{P} \leq 0,05)$ en el recuento de leucocitos totales entre el grupo G1 v/s G2 y G1 v/s G3 y los grados de las lesiones pulmonares totales evidenciaron diferencias estadísticamente significativas $(\mathrm{P} \leq 0,05)$ entre los tres grupos de estudio. Las lesiones histopatológicas pulmonares mostraron diferencias estadísticas relevantes sólo entre G1 y G3 (P $\leq 0,05)$. En este trabajo se verifican diferencias importantes del comportamiento entre el aislado de campo y el serotipo 5 ATCC, sobre los cambios hematológicos y las lesiones macroscópicas e histopatológicas ocasionadas por ellos, lo cual podría indicar una mayor virulencia y patogenicidad del aislado nacional. Se espera en un futuro próximo serotipificar este aislado nacional de App.
}

\section{AGRADECIMIENTOS}

Los autores desean agradecer a las Srtas. Daniela Rojas, T.M., y Aura Villamil, microbióloga de la Universidad de Concepción, y al Sr. Andrés Vergara, SAG y autoridades del Servicio Agrícola y Ganadero (SAG) por el apoyo brindado para la realización del trabajo. 


\section{REFERENCIAS}

Andreasen M, J Nielsen, P Baekbo, P Willeberg, A Botner. 2000. A longitudinal study of serological patterns of respiratory infections in nine infected Danish swine herds. Prev Vet Med 45, 221-235.

Bertram T. 1988. Pathobiology of acute pulmonary lesions in swine infected with Haemophilus (Actinobacillus) pleuropneumoniae. Can Vet J 29, 574-577.

Buret A, E Nerland, J Leblanc, D Morck, J Merrill, M Paradis, P Dick. 2004. Pro-apoptotic and anti-inflammatory effects of oral tilmicosin in the Actinobacillus pleuropneumoniae-infected porcine lung. Am Ass Swin Vet 3, 135-138.

Chiers K. 2003. Respiratory diseases: Contagious pleuropneumonia control. Pig Progress 19, 22-23.

Cho S, K Jung, J Kim, Y Ha, C Chae. 2005. Expression of mRNA encoding interleukin (IL)-10, IL-12p35 and IL-12p40 in lungs from pigs experimentally infected with Actinobacillus pleuropneumoniae. Vet Res Commun 29, 111-122.

Ciprián A, D González, G Colmenares, C Camacho, H Lara, F Parrodi, T Alcántara, A Altamirano, S Juvenal, A Sánchez, M López, M Ezquivel, D Ramos, D Mendoza, A Mendoza, C Álvarez, R Hernández, D Oliva, C Rodríguez, D Trujillo, A Vargas, M Trujillo, E Hernández-Baumgarten, S Mendoza. 2004. The Schwartzman Sanarelli phenomenon in pigs that are either vaccinated or infectedvaccinated and challenged with Actinobacillus pleuropneumoniae: I. Pathogenesis study. Proceedings of the $18^{\text {th }}$ IPVS Congress, Hamburg, Germany, Pp 207.

Dreyfus A, A Schaller, S Nivollet, R Segers, M Kobisch, L Mieli, V Soerensen, D Hüssy, R Miserez, W Zimmermann, F Inderbitzin, J Frey. 2004. Use of recombinant ApxIV in serodiagnosis of Actinobacillus pleuropneumoniae infections, development and prevalidation of the ApxIV ELISA. Vet Microbiol 99, 227-238.

Dubreuil D, M Jacques, K Mittal, M Gottschalk. 2000. Actinobacillus pleuropneumoniae surface polysaccharides: their role in diagnosis and immunogenicity. Anim Health Res Rev 1, 73-93.

Fenwick B, B Osburn, H Olander. 1986. Isolation and biological characterization of two lipopolysaccharides and a capsular enriched polysaccharide preparation from Haemophilus pleuropneumoniae. Am J Vet Res 47, 1433-1441.

Fittipaldi N, A Broes, J Harel, M Kobisch, M Gottschalk. 2003. Evaluation and Field Validation of PCR Tests for Detection of Actinobacillus pleuropneumoniae in subclinically Infected Pigs. $J$ of Clin Microbiol 41, 5085-5093.

Glantz SA. 2005. Another approach to analysis of variance. In: Glantz SA (ed). Primer of Biostatistics. $5^{\mathrm{a}}$ ed. McGraw-Hill Medical Publishing, Washington D.C., USA, Pp 298-333.

Gottschalk, M. 1998. The diseases: Actinobacillus pleuropneumoniae. Pig progress 14, 34-35.

Haesebrouck F, K Chiers, I Van Overbeke, R Ducatelle. 1997. Actinobacillus pleuropneumoniae infections in pigs: the role of virulence factors in pathogenesis and protection. Vet microbiol 58, 239-249.

Jacobsen I, J Gerstenberger, A Gruber, J Bossé, P Langford, I HennigPauka, J Meens, G Gerlach. 2005. Deletion of the ferric uptake regulator fur impairs the in vitro growth and virulence of Actinobacillus pleuropneumoniae. Infect immun 73, 3740-3744.
Kiorpes A, M Mirsky, P MacWilliams, L Bäckström, M Collins. 1989. Blood gas stability and hematological changes in experimentallyinduced acute porcine pleuropneumonia. Can J Vet Res 53, 95-99.

Kiorpes A, P MacWilliams, D Schenkman, L Bäckström. 1990. Blood gas and hematological changes in experimental peracute porcine pleuropneumonia. Can J Vet Res 54, 164-169.

Koyama T, H To, S Nagai. 2007. Isolation of Actinobacillus pleuropneumoniae serovar 15-like strain from a field case of porcine pleuropneumonia in Japan. $J$ Vet Med Sci 69, 961-964.

Liggett AD, Harrison LR, Ferrel RL. 1987. Sequential study of lesion development in experimental Haemophilus pleuropneumoniae. Res Vet Sci 42, 204-212.

Losinger W. 2005. Economic impacts of reduced pork production associated with the diagnosis of Actinobacillus pleuropneumoniae on grower/finisher swine operations in the United States. Prev Vet Med 68, 1-13.

Lumsden JN. 2000. Reference values. In: Feldman BF, Zinkl JG, Jain. Lippincott NC (eds). Schalm's veterinary hematology. $5^{\text {th }}$ Lippincott Williams \& Wilkins, Baltimore MD, USA, Pp 12-16.

Maes D, K Chiers, F Haesebrouck, H Laevens, M Verdonck, A De Kruif. 2001. Herd factors associated with the seroprevalences of Actinobacillus pleuropneumoniae serovars 2, 3 and 9 in slaughter pigs from farrow-to-finish pig herds. Vet Res 32, 409-419.

Muñoz D, M Quezada, A Ruiz. 2008. Estudio del comportamiento serológico de Actinobacillus pleuropneumoniae (App) en planteles porcinos comerciales de la zona central de Chile. Arch Med Vet 40, 147-153.

Olivares P, A Morgado. 1988. Isolation and serotyping of Haemophilus pleuropneumoniae in three porcine pleuropneumonia outbreaks in central Chile. Arch Med Vet 20, 147-152.

O'Reilly T, D Niven. 2002. Levels of nicotinamide adenine dinucleotide in extracellular body fluids of pigs may be growth-limiting for Actinobacillus pleuropneumoniae and Haemophilus parasuis. Can $J$ Vet Res 67, 229-231.

Ramírez E, A Ruiz, A Islas, C Lecocq, L Carrasco, M Quezada. 2006. Características hematológicas y patológicas de cerdos inoculados experimentalmente con el aislado chileno del virus síndrome respiratorio y reproductivo porcino. Arch Med Vet 38, 151-159.

Sanford E. 1998. Actinobacillus pleuropneumoniae Pneumonia and A. suis: an update. Proceedings of the $29^{\text {th }}$ Am Ass Swin Vet Meeting, Des Moines, Iowa, USA, Pp 357-360.

Sánchez M, L Cuevas, A Morgado. 1986. Pleuroneumonía porcina: aislamiento de Haemophilus pleuropneumoniae en Chile. Avances Med Vet 1, 1-3.

Sánchez R, J Monserrat, A Prieto, E Reyes, M Álvarez, M Sánchez. 2005. Balance entre citocinas pro y antiinflamatorias en estados sépticos. Med intensive 29, 151-158.

Straw B, D Taylor, S D'Allaire, W Mengeling. 2002. Actinobacillus pleuropneumoniae. En: Editorial Interamericana (ed). Enfermedades del cerdo. $8^{\mathrm{a}}$ ed. Buenos Aires, República Argentina, Pp 401-406.

Vadillo S, S Píriz, E Mateos. 2002. Géneros Actinobacillus, Haemophilus, Pasteurella y Mannheimia. En: Vadillo S, Píriz S, Mateos E (eds) Manual de Microbiología Veterinaria. $1^{\text {a }}$ ed. Edigrafos, S. A. Madrid, España, Pp 145-159.

Wang F, J Yang, S Hung, I Pan. 2001. In vitro migratory responses of swine neutrophils to Actinobacillus pleuropneumoniae. Exp Anim 50, 139-145. 